\title{
REDE DE AÇÕES PARA IMPLEMENTAÇÃO DO SISTEMA PLANTIO DIRETO NA PALHA NA REGIÃO CENTRO-SERRANA DO ESPÍRITO SANTO
}

\author{
Douglas Vianna Bahiense ${ }^{1}$ \\ Lucinéia Laurett ${ }^{2}$ \\ Jacimar Luis de Souza ${ }^{3}$ \\ Evelson Sanche Muniz ${ }^{4}$ \\ Horácio Vicente Caetano Gonçalves ${ }^{5}$ \\ Tálita Vieira Fideles ${ }^{6}$ \\ Juliana Schumacher ${ }^{7}$ \\ Luiz Fernando Favarato ${ }^{8}$ \\ Maria da Penha Angeletti ${ }^{9}$
}

Resumo: O sistema plantio direto na palha - SPD ou SPDP pode representar um diferencial tecnológico na diminuição da dependência de insumos externos. Na realidade agrícola da Região Serrana do Espírito Santo, os agrossistemas produtores de hortaliças e grãos estão em estabelecimentos familiares que, em sua maioria, adotam as práticas convencionais de agricultura. Neste contexto foi criada uma Rede de ações na aplicação dos princípios do SPD. O presente trabalho relata a constituição e o funcionamento desta rede no período 2014-2016. Na metodologia, deu-se a formação a partir da necessidade de juntar os agricultores familiares, técnicos e pesquisa a partir da necessidade de expansão do projeto. A Rede tem sido um importante instrumento de fomento ao SPD, com tecnologia e sementes, porém ainda incipiente, na troca entre os participantes, para se ouvir os ouvir os agricultores, assistência técnica e pesquisa, também para projetos de fomento de sementes, de roçadeiras e consolidação das práticas. Viu-se a necessidade de acompanhamento/visitas regulares periódicas às áreas da Rede, e de capacitação continuada.

Palavras-chave: Sistema plantio direto na agricultura familiar; Fomento tecnológico por organização social; Pesquisa aplicada; Formação de conhecimentos; Sindicato de trabalhadores rurais.

\footnotetext{
1 Instituto Capixaba de Pesquisa Assistência Técnica e Extensão Rural - INCAPER/Centro Regional de Desenvolvimento Rural Centro Serrano, Brasil. E-mail: douglas.bahiense@yahoo.com.br.

2 Sindicato dos Trabalhadores Rurais Agricultores e Agricultoras Familiares de Santa Maria de Jetibá - STRSMJ, Brasil. E-mail: laurett24@hotmail.com.

3 Instituto Capixaba de Pesquisa Assistência Técnica e Extensão Rural - INCAPER/Centro Regional de Desenvolvimento Rural Centro Serrano, Brasil. E-mail: jacimarsouza@yahoo.com.br.

${ }^{4}$ Sindicato dos Trabalhadores Rurais Agricultores e Agricultoras Familiares de Santa Maria de Jetibá - STRSMJ, Brasil. E-mail: evelsonsanche@bol.com.br.

${ }^{5}$ Escola Família Agrícola de São João do Garrafão - EFASJG, Brasil. E-mail: horaciocaetano@yahoo.com.br.

6 Instituto Capixaba de Pesquisa Assistência Técnica e Extensão Rural - INCAPER/Centro Regional de Desenvolvimento Rural Centro Serrano, Brasil. E-mail: talitafideles@gmail.com.

7 Sindicato dos Trabalhadores Rurais Agricultores e Agricultoras Familiares de Santa Maria de Jetibá - STRSMJ, Brasil. E-mail: jujusmb@hotmail.com.

8 Instituto Capixaba de Pesquisa Assistência Técnica e Extensão Rural - INCAPER/Centro Regional de Desenvolvimento Rural Centro Serrano, Brasil. E-mail: Iffavarato@gmail.com.

${ }^{9}$ Instituto Capixaba de Pesquisa Assistência Técnica e Extensão Rural - INCAPER/Centro Regional de Desenvolvimento Rural Centro Serrano, Brasil. E-mail: penhangeletti@incaper.es.gov.br.
} 